DOI 10.37882/2223-2982.2021.02.17

\title{
ГУМАНИТАРНАЯ ЭКСПЕРТИЗА КАК ОЦЕНКА КАЧЕСТВА РЕАЛИЗАЦИИ ОБРАЗОВАТЕЛЬНОГО ПРОЦЕССА В ВУЗЕ
}

\section{HUMANITARIAN EXPERTISE AS AN ASSESSMENT OF THE QUALITY OF IMPLEMENTATION OF THE EDUCATIONAL PROCESS AT THE UNIVERSITY}

\section{Matveeva}

Summary: The article deals with the concepts of "expertise", "humanitarian expertise". The article substantiates the specifics of humanitarian expertise, which consists in supporting the subjects of the educational process. The necessary criteria for the formation of the experience of humanitarian expertise are identified.

Keywords: expertise, humanitarian expertise, educational program of the university, subjects of the educational process, experience of humanitarian expertise, criteria for the formation of experience of humanitarian expertise.
Матвеева Ирина Алексеевна

Аспирант, ФГБОУ ВО "Волгоградский государственный социально-педагогический университет", г. Волгоград matveevaia@volgoduma.ru

Аннотация: В статье рассмотрены понятия «экспертиза», «гуманитарная экспертиза». Обосновывается специфика гуманитарной экспертизы, которая состоит в осуществлении поддержки субъектов образовательного процесса. Выявлены необходимые критерии сформированности опыта гуманитарной экспертизы.

Ключевые слова: экспертиза, гуманитарная экспертиза, образовательная программа ВУЗа, субъекты образовательного процесса, опыт гуманитарной экспертизы, критерии сформированности опыта гуманитарной экспертизы.

Сначала рассмотрим понятие «экспертиза». Обратимся к исследователям данной проблематики.

В Большой Советской Энциклопедии понятие экспертизы определяется как «исследование экспертами каких-либо вопросов, решение которых требует специальных познаний в области науки, техники, искусства и т.д.» $[2]$.

Если обратиться к словарю русских синонимов [1], то можно увидеть достаточно близкие по своему значению слова «экспертиза», «консультация», «консультирование», «аудит», «критика», «рецензия».

Слободчиков В.И., Исаев Е.И. считают, что образование является определяющим фактором для перспективного развития устойчивых гуманистических идей [8].

Такой вид экспертизы в образовании обусловлен его коммуникативной природой, а также отличительными чертами гуманитарной системы. Традиционно сложилось, что российский ВУЗ - это ключевой фактор, определяющий духовную жизнь общества. Но в современном мире человек не стремится реализовать свой духовный и творческий потенциал.

Солнцева О.В. также полагает, что с помощью гуманитарной экспертизы возможно определить пути совершенствования образовательной программы и ее дальнейшее развитие. В контексте своего исследования она 
понимает гуманитарную экспертизу как «понимающую экспертизу». Проектирование образовательных результатов сосредоточено на оценке качества образовательной деятельности, с учетом индивидуальных особенностей и потребностей обучающихся [9].

Канищева Л.Н., проводя свое исследование, выделила следующие признаки, требующие проведения гуманитарной экспертизы: «наличие субъект-субъектных отношений; наличие ситуации неопределенности или противоречивости; наличие процесса освоения» [4].

Луков В.А. считает, что гуманитарная экспертиза определяется как опережающее реагирование, которое призвано выявить возможные риски нововведений, когда данные риски не очевидны и не осознаются в обществе. Эксперт при проведении гуманитарной экспертизы должен быть способен адекватно выражать интересы субъектов образовательного процесса [5].

Пуденко Т.И. в контексте своего исследования обосновывает важность гуманитарной экспертизы, исходя из того, что в первую очередь родителям важно знать, доступна ли программа для понимания обучающимся, соответствует ли она индивидуальным особенностям их детей [7].

Опираясь на мнения вышеназванных ученых, можно заключить, что гуманитарная экспертиза - это процедура оценки и анализа объекта с позиции его гуманитарного качества, процесс и результат оценки образовательных предметов, объектов, процесса и результатов. Эта процедура осуществляется с учетом последовательности этапов и специализированных знаний, чтобы получить экспертное заключение.

Гуманитарная экспертиза - это вид профессиональной деятельности, направленный на аргументацию экспертных решений в условиях неопределенности или риска, которые выявлены экспертом на основании исследований образовательных объектов.

\section{Такая экспертиза должна стать установкой ВУЗа.}

Гуманитарная экспертиза включает необходимые этапы ее проведения: контроль, анализ, диагностику, разработку замечаний/предложений по усовершенствованию реализации образовательного объекта. При этом важно учитывать социокультурные нормы качества предоставляемых образовательных услуг.

Гуманитарная экспертиза не должна восприниматься субъектами образовательного процесса как «ревизия» или контроль. Эта экспертиза предполагает субъектсубъектные отношения между участниками процесса и экспертами. Эксперт должен понять, насколько «чело- вечной» жизнью живут обучающиеся и преподаватели: сохраняют и укрепляют ли они свое физическое, психическое и нравственное здоровье, какие ресурсы имеет образовательное учреждение для перспективного становления культурно-развивающей личности? Если таких ресурсов недостаточно, то эксперт должен предложить, что возможно сделать для этого в современных условиях.

Таким образом, гуманитарная экспертиза рассматривается как образовательная диагностика (различные технологии ее проведения); как исследование социальной стороны жизнедеятельности субъектов образования; исследование образовательных программ, а также как разносторонняя экспертиза.

Развитие системы гуманитарных ценностей предполагает формирование опыта реализации экспертной процедуры: «прогнозирование, определение критериев проведения гуманитарной экспертизы, комплексный анализ результатов и возможных последствий; осознание профессиональной ответственности за принятие решений; развитие профессиональной устойчивости и возможность реализовывать прорыв в смежных областях своей профессиональной деятельности» [10].

Таким образом, анализ опыта исследователей позволил нам выявить необходимые критерии сформированности опыта гуманитарной экспертизы:

- оптимальный выбор стратегических шагов, методов и технологии осуществления экспертизы;

- прогноз результатов взаимодействия субъектов/ участников в реализации образовательной программы для общества;

- прогноз перспективного развития проверяемого объекта;

- осуществление гуманитарной экспертизы, предполагающей выявление соответствия образовательной программы гуманитарным нормам;

- оценивание дальнейших последствий проведенной экспертной проверки;

- предложения и замечания эксперта по совершенствованию реализации образовательной программы;

- формулировка заключения эксперта.

Анализ литературы также позволяет нам выделить основные функции гуманитарной экспертизы в контексте образовательного процесса:

- объясняющая (помощь субъектам образовательного процесса в осмыслении своей деятельности);

- защитная (осознание того, что права и интересы личности должны быть на первом месте);

- развивающая (цель экспертизы не только в выявлении потенциала образовательного процесса, но и в получении опыта для перспективной образо- 
вательной деятельности);

- оценочная (самая важная и необходимая функция экспертизы, без которой она теряет свой смысл);

- прогностическая (описание будущих результатов);

- функция легализации (признание экспертируемого образовательного процесса, его поддержка и дальнейшее развитие).

Гуманитаризация образовательной среды ВУЗа обусловлена «осознанием смысла и ценности образования, его высшей миссии, условиями для развития личности обучающегося, её самооценки, стремлением к самосовершенствованию, направленностью процесса освоения образовательной программы на воспитание гуманистического мировоззрения, где главной ценностью является личность обучающегося: его потенциалы и достижения, нравственность в освоении содержания об- разовательной программы, приобретение толерантного мышления, готовность принимать решения в противоречивых ситуациях» [12].

Гуманитарная экспертиза способствует гуманистическому развитию субъектов образовательного процесса и образовательного учреждения в целом. Итог такой экспертизы - это обоснование перспективных возможностей и путей совершенствования жизнедеятельности ВУЗа.

Таким образом, мы считаем, что введение гуманитарной экспертизы в работе ВУзов будет способствовать целостной реализации современных целей образования, поскольку гуманитарная отличается от других видов экспертиз тем, что она центрирует свое внимание на интересах субъектов, непосредственных участников образовательного процесса.

\section{ЛИТЕРАТУРА}

1. Абрамов, Н. Словарь русских синонимов и сходных по смыслу выражений. - М.: Русские словари, 1999. http://ivanov-portal.ru/ (дата обращения: 06.04.2020).

2. Большая Советская Энциклопедия. http://bse.sci-lib.com/ (дата обращения: 06.04.2020).

3. Иванов Д.В. Психолого-педагогические подходы к исследованию образовательной среды / Д.В. Иванов // Мир психологии, 2006. - № 4. - С. 167-174.

4. Канищева Л.Н. Гуманитарная экспертиза как метод формирования у будущих программистов гуманитарного восприятия научно-технических проблем / Л.Н. Канищева // Известия Волгоградского государственного педагогического университета, 2008. - №6. - С. 59-62.

5. Луков В.А. От экспертизы социальной к гуманитарной экспертизе / В.А. Луков // Знание. Понимание. Умение, 2012. - №2. URL: https://cyberleninka.ru/ article/n/ot-ekspertizy-sotsialnoy-k-gumanitarnoyekspertize (дата обращения: 24.04.2020).

6. Матвеева И.А. Этапы мониторинга в управлении качеством организации образовательного процесса в ВУзе // Научное отражение. 2017. - №3 (7). - С. $17-18$.

7. Пуденко Т.И. Общественная экспертиза образовательной программы школы как ресурс гуманистической педагогики и эффективного управления // 4и0. - 2015. - №4 (45). URL: https://cyberleninka.ru/article/n/obschestvennaya-ekspertiza-obrazovatelnoy-programmy-shkoly-kak-resurs-gumanisticheskoypedagogiki-i-effektivnogo-upravleniya (дата обращения: 02.05.2020).

8. Слободчиков В.И. Основы психологической антропологии / В.И. Слободчиков, Е.И. Исаев // Психология развития человека: развитие субъективной реальности. М.: Школьная пресса, 2000. - 421 с.

9. Солнцева О.В. Гуманитарная экспертиза оценки качества основной образовательной программы дошкольного образования / 0.В. Солнцева // Сборник материалов Ежегодной международной научно-практической конференции «Воспитание и обучение детей младшего возраста», 2016. - №5. - С. 909911.

10. Эрдынеева К.Г. Образовательная среда ВУЗа как объект гуманитарной экспертизы / К.Г. Эрдынеева // Гуманитарный вектор. Серия: Педагогика, психология, 2012. - №1. URL: https://cyberleninka.ru/article/n/obrazovatelnaya-sreda-vuza-kak-obekt-gumanitarnoy-ekspertizy (дата обращения: 16.04.2020).

(c) Матвеева Ирина Алексеевна (matveevaia@volgoduma.ru).

Журнал «Современная наука: актуальные проблемы теории и практики» 